\title{
ESL and Canadian Multiculturalism: Multilingual, Intercultural Practices for the 21st Century
}

\author{
Seonaigh MacPherson, Diana Turner, Ranya Khan, \\ Warren Hingley, Ann Tigchelaar, and Lori Dustan Lafond
}

\begin{abstract}
This article is a collaborative initiative of the TESL profession in Manitoba. It reflects the authors' attempts to articulate the role of the ESL teaching profession and practice in Canadian multiculturalism. Recognizing ESL teachers' historical roles as agents of assimilation, the authors consider how the field can reorient itself to serve instead the equity and diversity needs of Canadians. They argue that this involves the promotion of more multilingual, intercultural approaches to ESL/SESD. The article begins by considering the model of multiculturalism promoted by Canadian constitutional and legislative policies over the last decades and the key role the TESL field can and does play in this mandate. The article continues on to recommend expanding the potential stakeholders included as ESL students and professionals. This is not done to expand the profession so much as to enhance the professional ethics and responsibilities of the field.
\end{abstract}

Cet article représente une collaboration par des membres de la profession TESL au Manitoba et il reflète leurs efforts visant l'expression du rôle que jouent la profession et la pratique de l'enseignement $A L S$ dans le contexte du multiculturalisme au Canada. Reconnaissant que le rôle historique des enseignants ALS est celui d'agents d'assimilation, les auteurs se penchẹnt sur la façon dont le domaine peut changer d'orientation pour être au service de l'équité et la diversité des Canadiens. Ils proposent qu'un tel changement impliquerait la promotion d'approches plurilingues et interculturelles à l'enseignement de l'anglais langue seconde et de l'anglais standard comme second dialecte. L'article débute par une considération du modele du multiculturalisme que mettent en valeur les politiques constitutionnelles et législatives depuis plusieurs décennies et la fonction cruciale du domaine TESL dans cette mission. Les auteurs poursuivent en préconisant le développement du champ d'intervenants potentiels d'élèves et de professionnels ALS, non pas pour agrandir la profession mais plutôt pour rehausser les devoirs et les responsabilités professionnels de ce domaine.

\section{Introduction: ESL by Any Other Name}

Unlike the rose, the English language by any other name may not be the same. What is this peculiar penchant in our field for describing the language 
we teach with one of an increasing number of acronyms, ${ }^{1}$ but never simply English language education? Why do native English speakers simply study English, whereas non-native speakers study one of a variant of labels for English determined by the students' locations and identities? The field that most closely approximates this obsession with acronyms is the information technology (IT) sector, which may not be a coincidence. How easy to speak of ESL for IT; I mean, who has time to waste on words when progress beckons? And why is the teaching of English to non-native speakers differentiated from teaching other languages to non-native speakers: TESL versus modern, heritage, Aboriginal, or "world" language education, for example? Why does English merit a category of its own? Is it by virtue of its status as an international language or an official language in so many former British or now American colonial states? Or is it because people who speak English have the power to elevate its importance? This has led critics inside and outside our profession to recommend renaming our activities to, for example, multilingual or intercultural language education (Coelho, 2003; Goldstein, 2003; LoBianco, Liddicoat, \& Crozet, 1999). This shift of emphasis from ESL to multilingualism/interculturalism reflects a distrust many feel for the colonial and assimilation history of English language education.

This article is the fruit of a series of collaborative discussions between representatives from TESL Manitoba and TEAM (Teaching English to Adults of Manitoba). These are the two TESL professional organizations in Manitoba for the K-adult ESL and adult ESL teaching sectors respectively. The article is an elaboration of a position paper we co-authored as a response to Manitoba Education, Citizenship, and Youth's (MECY) draft policy proposal Diversity and Equity in Education: An Action Plan for Ethnocultural Equity (http://www.edu.gov.mb.ca/ks4/docs/discuss/diversity/).

TESL Manitoba and TEAM recognize advocacy as part of their mandated activities as TESL professional organizations. As we move toward increasing government accountability and controls exercised through standardized curricula and teacher certification, it is critical that we work together as professionals across the K-S4 (K-12) ESL, adult ESL, and TESL sectors to provide research, awareness, and critical feedback and critical stances toward the development of assimilative ESL policies, both provincial and federal.

Although this article originated as a background paper for Manitoba's diversity and equity educational policies, we wrote it as a proposed mandate for the development of our field in Canada. In many respects, Manitoba is a microcosm of Canada. It is home to strong and intact Indigenous and Metis communities, whose members are increasingly relocating to urban centers. At the same time, the province is responding to the continuing influx of an estimated 10,000 newcomers per year. As early as 1996, the city of Winnipeg had the third largest proportion of Aboriginal and visible-minority children and youth in the country, following Vancouver and Toronto (Mato \& Valen- 
tine, 1999). In this respect, we need to educate against racism, not just for enhanced diversity. These various challenges and opportunities situate us, perhaps uniquely, to respond to the full spectrum of potential diversity and equity issues facing the TESL field across Canada.

\section{Equity and Diversity in T/ESL}

This article addresses the emerging relationship in Canada between the teaching of English as a second language (TESL) and multiculturalism. Canada has a long history of assimilation through education that has pressured or forced both Indigenous and new Canadians to forfeit their first language and culture to function in the anglicized norms of the society (Burnaby, 2002). Even the "founding English" settlers and settlements often were not predominantly English-speaking, a fact often obscured in historical representations of Canada. Ironically, Gaelic-speaking Scots and Irish from the British Isles were some of the first victims of language loss through forced occupation, migration, and colonial English-language education. This early instance of assimilation through English language education continued in later generations with the forced assimilation of Indigenous peoples and other non-English speaking immigrants. The anglicizing norms were, and continue to be, reinforced through the ubiquitous use of English as the language of instruction (Tollefson \& Tsui, 2004); inadequate support for multilingual studies and maintenance (Kouritzin, 1999); and biased Eurocentric curricular contents (Willinsky, 2000).

Since the 1970s, with the passing of various federal, provincial, and constitutional human rights documents in Canada, multiculturalism (diversity) and human rights (equity) have become defining principles guiding the policies and provisions of the nation state. All educators, but especially ESL/SESD teaching professionals entrusted with the education of new and Indigenous Canadians with a non-official first language, are implicitly, if not explicitly, asked to understand their roles and responsibilities in the broader mandate of multiculturalism and human rights. This responsibility was reinforced in 1982 with the passing of the Canadian Charter of Rights and Freedoms, when Canada took a significant step toward correcting some its colonial legacy: externally by repatriating its constitution, and internally by entrenching certain individual rights related to equality and diversity as constitutional guarantees.

Yet the Canadian Charter of Rights and Freedoms also reinforced certain other aspects of Canada's colonial legacy by giving official status to the English and French languages and to Protestant or Roman Catholic separate schooling. Ever since, ESL education has assumed a paradoxical place in the Canadian equity and diversity agenda. With respect to equity, the shift to English enacted through mainstream education disadvantages non-Englishspeaking students and tends to culminate in cultural and linguistic assimila- 
tion. On the other hand, access to one of the official languages-English or French-is nonetheless a key component of realizing equitable conditions for well-being in Canada. In this sense, English language education at once facilitates and undermines equity, and by encouraging the loss of first languages and cultures, potentially disadvantages people from full social and economic participation in Canada and global communities. Similarly, ESL holds an ambiguous place in Canadian diversity policies and practices. On the one hand, the shift to English can pose a potential challenge or threat to diversity by steadily distancing individuals from participation in their communities and cultures of origin; on the other hand, it offers the potential to assist them to negotiate diversity as multilingualism and interculturalism.

Recognizing the potential benefits and threats of ESL to equity and diversity, the Canadian TESL profession needs to clarify its relationship to federal, provincial, and constitutional multicultural policies and practices. Indeed, this challenge holds true for worldwide professionals insofar as the promotion and teaching of subtractive approaches to English as a second language continues to pose a major threat to linguistic and cultural diversity globally (Crystal, 2000). This history of educational assimilation through ESL requires more than a critical historical inquiry; it calls for a meaningful professional dialogue on how we can reframe our professional activities to bring them into accord with the broader multicultural aspirations and values of Canada and the world. Too often the word multiculturalism invokes a blank stare, as if it were a moniker for little more than political correctness. This article is intended to counter this view by exploring the deep significance of the shift toward acknowledging diversity through a multicultural and intercultural approach to teaching ESL.

\section{Canadian Multiculturalism and Education}

Most formal education and schooling in Canada is publicly funded and expected to serve public ends. The state bears some responsibility for defining these public ends for educators and for providing the means to realize them. In Canada, various constitutional and legal documents have emerged to fulfill this responsibility. The Canadian Charter of Rights and Freedoms of 1982 and the Multiculturalism Act of 1988 legally entrench an official national identity founded on multiculturalism and human rights. This distinctly Canadian approach to multiculturalism has implicit citizenship implications to support and respect one another actively, beyond mere tolerance. Defining the values that bond a multicultural citizenry without overriding the respect for diversity and individual rights is no small challenge. In 1991, a Canadian government commission attempted to do so by identifying seven common values shared by Canadians (Citizen's Forum on Canada's Future, 1991): a belief in equality and fairness; a belief in consultation and dialogue; the importance of accommodation and tolerance; support for diversity; com- 
passion and generosity; attachment to the natural environment; and a commitment to freedom, peace, and non-violent change. These official Canadian values are not simply an ideal invention of the state either; to a considerable extent, they embody the "unofficial" lived value and identity experiences and struggles of Canadians.

What is the uniquely Canadian version of multiculturalism? Drawing on Trudeau's 1971 statement to the House of Commons on "Multiculturalism with a Bilingual Framework," Magsino (1995) identifies four aspects of Canadian multicultural policies that work together as checks and balances: (a) cultural retention; (b) cultural sharing; (c) equality of opportunity; and (d) individual freedom. These reflect the four principles of diversity, interculturalism, equity, and choice. In general, diversity and interculturalism are safeguarded through multicultural policies and equity and choice through human rights. Constitutionally, this is mirrored in the attempt to wed multiculturalism with human rights in the Canadian Charter of Rights and Freedoms. In this respect, Canadian multiculturalism is not simply an attempt to protect cultural differences, but an active attempt to articulate and foster a distinct and unifying Canadian identity, citizenry, and system of social values. This is accomplished by various means, but principally by safeguarding access to one of two official languages, either French or English; by protecting native languages and cultures; and by a commitment to human rights as common basis for our shared values, ethics, and laws.

\section{TESL as Multicultural Practice}

The teaching and learning of English as a second language plays a central role in the realization of Canadian multiculturalism. ESL teachers can profoundly affect students' views of their first languages and cultures, and thereby can affect whether they pursue multilingual/intercultural outcomes or subtractive assimilation. Not only can they teach "Canadian" human rights values, but also how to become intercultural, that is, how to move across cultures in a way that is tolerant of conflicting perspectives and deeply respectful of people's lived differences. In the service of equity, ESL education avails new immigrants, refugees, and international students of an official language of Canada (and the world for that matter) and associated opportunities. ESL educators are among the first Canadians these students encounter when they settle in Canada, and they are entrusted with teaching students how to negotiate the language, culture, and values of Canada. In this way, they inform students of their choices and affect what choices students make. For these reasons and more, it is important to clarify TESL's role in the broader context of Canada's vision of itself as a multicultural state. TESL's role in the four aspects or principles of Canadian multiculturalism can be conceived in the following terms. 


\section{Multiculturalism as Cultural Retention (Diversity)}

There was a time when the intended outcome of English language education for non-native speaking Aboriginals and immigrants was assimilation. Schools and educational programs understood the active and even forced exclusion of native languages and cultures as part of their pedagogical mandate. With time, this was moderated as educators reconceived their role as the integration, rather than assimilation, of immigrants and Aboriginals into a presumed mainstream Canadian culture and official language. In 1971, this integration policy gave way to a policy of multicultural accommodation as Trudeau committed the government of Canada to play a role to "assist all Canadian cultural groups that have demonstrated a desire and effort to continue to develop" (Magsino, 1995, p. 256). Now, as we face the imminent loss of languages nationally (Kouritizin, 1999) and globally (MacPherson, 2003), educators across the curriculum have begun to reconceive their mandate to include cross-cultural accommodation, cultural awareness, and interculturalism (LoBianco et al., 1999). For TESL, this requires that we reconceive our profession more broadly as part of the promotion of multilingualism and first-language and cultural maintenance, as a means of adding rather than substituting English (Coelho, 2003; Goldstein, 2003).

\section{Multiculturalism as Cross-Cultural Understanding (Interculturalism)}

The commitment of Canada to cross-cultural sharing is an attempt to build national unity through rather than in spite of its commitment to diversity and cultural retention. Cross-cultural understanding arises from more than exposure to mere information; it is an active appreciation of the unique histories, world views, and perspectives of people of diverse backgrounds. It arises from more than tolerance; it is a function of the active and respectful engagement of human beings across differences. In this respect, cross-cultural sharing is a precondition for cross-cultural understanding, and effective cross-cultural sharing depends on interculturalism. Interculturalism is distinct from multiculturalism, the mere presence of multiple cultures in a particular group or society. Interculturalism involves participating in two or more cultures and the ability to move between and across them effectively and with some degree of intention. It includes the development of cultural creativity, that is, of hybrid, unique cultural alternatives arising from knowledge of two or more cultures. Such intercultural creativity is the fruit of meta-cultural awareness, that is, the awareness that our experience is conditioned in a culturally-and historically-specified world view. Cross-disciplinary research exists on various dimensions of interculturalism, ranging from intercultural identity formation (Bennett, 1986), to intercultural communication (Kim, 2001), and intercultural language education (LoBianco et 
al., 1999). Interculturalism offers a strategy for fostering unity while safeguarding diversity.

When we learn a new language, especially in immersion programs, we have the opportunity to cultivate interculturalism; yet as Bennett (1986) argues, such intercultural awareness does not develop and progress spontaneously from cross-cultural contact. It needs to be explicitly taught and cultivated, or there is a danger that people will fossilize in various stages of ethnocentricism through to cultural encapsulation. The fully realized ethnorelative, intercultural position appears to depend to some degree on formal education in culture and is characterized by what Bennett calls "constructive marginalization." This state involves an enhanced disengagement along with greater choice in cultural participation, thereby transforming what could be a negative state of cultural marginalization and ennui into a condition of enhanced freedom and happiness. ESL and other second-language classrooms offer conditions to foster intercultural awareness and communication explicitly. Accordingly, many TESL professionals have begun to reconceive their activities as part of a broader mandate to cultivate interculturalism (LoBianco et al., 1999).

At the same time, cross-cultural sharing depends on more than interculturalism; it also depends on an appreciation of shared values and experiences that go beyond our participation in certain local histories and cultures. ${ }^{2}$ The language of human rights provides a framework for considering our collective human identity and values, which include empathic sensibilities that both secular human rights and religious traditions promote (MacPherson \& Tigchelaar, 2004).

\section{Multiculturalism as Equality of Opportunity (Equity)}

Human rights, ${ }^{3}$ as defined in the Canadian Charter, protect both individual and communitarian rights, that is, both rights to cultural retention (including linguistic and educational rights) and individual rights to equity and choice. In that all persons in Canada are extended equal status under the Charter, they are given the right to participate fully and equitably in the life of Canada. Canada's commitment to this principle is reflected in the attempt to remove for newcomers all cultural and language barriers to full participation in Canadian society. This includes providing access to one of the official languages of Canada. Accordingly, more than perhaps any other of the four principles, TESL has the greatest implications for the provision of equality of opportunity for full participation in Canadian society. This is because competence in English is necessary for full and unimpeded participation in the Canadian economy and society outside Quebec. By explicitly making access to one of the official languages through education a right, the Charter stands as a potential challenge to any school board, division, or public education system that chooses to neglect the official language needs of its students. 


\section{Multiculturalism as Individual Freedom (Choice)}

Canadian multicultural policies are unique in championing communitarian and equality rights through protecting languages and cultures (cultural retention rights); nevertheless, like most human rights documents, they ultimately protect individuals' freedom of choice. Accordingly, Canadian multicultural policies safeguard individual choice in cultural and language community participation where possible, and although the promotion of cultural retention and cross-cultural sharing provide an opportunity to participate in multiple languages and cultures, whether people avail themselves of these opportunities is a matter of individual choice. Accordingly, protections for linguistic, cultural, and educational choice are implications of Canadian multiculturalism policies that need to be reflected in educational policies where possible.

\section{T/ESL as Multilingual, Intercultural Practice}

As TESL professionals, we view ourselves as English-language educators of multilingual and multicultural learners and communities with specific responsibilities emanating from this role. Although specifically responsible for teaching the English language to non-native speakers of English, our responsibilities go well beyond the scope of a limited focus on language instruction to include the following:

1. respecting and supporting students' native languages and cultures;

2. understanding multilingualism as a key component of Canadian multiculturalism (Goldstein, 2003) and ESL as a process of "adding English" (Coelho, 2003);

3. providing accessible English-language programs that offer the potential to develop English-language proficiency and opportunities;

4. developing curricula and programs that address the whole person, including cognitive and affective, not just linguistic, needs;

5. providing students with the knowledge, skills, and support to adjust to mainstream Canadian culture;

6. removing systemic and institutional barriers that prevent equitable access to all the services and opportunities available to their native-speaking counterparts (Kouritzin \& Mathews, 2002);

7. establishing school or higher educational communities that embrace diversity and inclusion (equity);

8. fostering in both students and teachers positive attitudes of empathy and compassion, as well as a critical anti-racist awareness, to cultivate attitudes of respect beyond mere tolerance;

9. teaching citizenship as part of a basic curriculum for all students, and focusing on the citizenship values of Canada, not merely the facts- 
these values include participatory democratic engagement, diversity, multiculturalism, equity, interculturalism, and human rights;

10. providing an intercultural education that offers the knowledge, skills, and values to move between and across multiple cultures, with sensitivity to the challenges posed by the need to negotiate multiple cultures and identities;

11. addressing the broader context of students' families and communities;

12. helping students to identify and address the challenging experiences they may have faced or continue to face as immigrants and refugees in Canada. These challenges may include sadness, loss and grief for the homes, careers, friends, and family members they have left behind; for the vibrant languages and cultures they may have known and thrived within; and for memories of loved ones who have died and other traumas arising from insurrections and war.

We recognize that these are ideals, and it will be a long journey to bring these responsibilities and aspirations to fruition in our programs and teaching. To do so requires critical inquiry and active questioning in all subject areas across the curriculum. It calls on both teachers and students to investigate and interrupt singular, narrow interpretations of history and contemporary cultural practices. It calls for greater bilingual and multicultural supports in both ESL and mainstream classes, but in such a way as to enhance intercultural communication across diverse student bodies, not just directed at moving minorities into the mainstream language and culture (Martin-Jones \& Saxena, 1995). Critical multiculturalism is a form of multiculturalism that is more sensitive to the true extent of the diversity of the empirical world, as well as the complex, non-essentialist nature of culture. As Kubota (2004) suggests, "As a socio-political movement, critical multicultural education aims for social transformation by seeking social justice and equality among all people rather than merely celebrating differences or assuming a priori that all people are equal" (p. 37). This expanded version of critical, transformative multicultural education requires that we move beyond the conventional or "official" version of our professional responsibilities. Just as our responsibilities expand in such a vision, so do the groups of students for whom we bear these responsibilities.

\section{T/ESL and diverse communities}

ESL is a language development issue, not a special-needs or disability issue; so it is important to identify how we go about classifying ESL students and teachers. In a critical multicultural perspective, ESL teachers understand themselves as accountable to all learners and potential learners, not just those in their classrooms. Indeed, this would include those marginalized and excluded from the entire institutions and systems in which they teach. At the same time, we do work in institutions that justifiably organize students 
according to their individual requirements. From this perspective, as TESL professionals, we see ourselves serving four student bodies in particular: (a) first and second generation immigrant and refugee students, families, and communities; (b) Aboriginal students, families, and communities; (c) Deaf students, families, and communities; and (d) international students. At least one or more of the authors have worked directly with each of these groups of students in the context of teaching ESL. On the basis of this experience, we have identified the unique considerations, methods, materials, and contextual knowledge required for each group.

\section{TESL and Immigrant Students}

The large number of immigrants being admitted to Canada without English requires a significant investment of funding and support to ensure an equitable and just future for both the students and Canada. Some of these students have limited literacy or education in their first language. In addition, some families in Canada choose to use a non-official language at home, and so the children require additional support in ESL at school. Another concern is that some students of second-generation immigrant families have had limited access to either their heritage or the English language at home and may be semilingual as a consequence, with specific needs arising from such a condition. Finally, some immigrant or refugee families are speakers of world Englishes and dialects from regions in the Caribbean, South Asia, Africa, and South America (e.g., Guyana) and need specialized Standard English as a Second Dialect (SESD) support. These varied concerns call on three areas for TESL.

Language development. Equity, as a key principle of Canadian multiculturalism, calls for continuing assessment and funding for all learners to meet their individual proficiency needs. Proficiency in this respect needs to be defined in the context of students' individual goals, aspirations, and potentials. This implies a commitment to educating students to an adequate level of academic proficiency, not merely conversational proficiency. Accordingly, language support needs to be understood in a continuum beyond high school graduation, with implications for extending language support beyond the K-S4 (K-12) levels. We need to extend English-language support to those with conversational skills to be able to engage effectively the oral and written uses of standard English for academic and workplace uses.

TESL in bilingual language programs. To respect cultural and linguistic retention as an implication of Canadian multiculturalism, we advocate the development of bilingual or dual-language programs in ESL (SESD) and heritage languages or dialects for communities with sufficiently large numbers of students. This would further Canada's formal constitutional, legal, and social commitment to accommodating and sustaining the cultures and languages of incoming immigrants and refugees across generations. Also, 
speakers of English dialects need support in standard English in a manner that respects their home dialect as a valued and legitimate language. Although SESD methods differ somewhat from ESL methods, the principle of teaching them with additive, multilingual outcomes is similar.

Implications for professional development. All teachers in Manitoba need special preparation to teach ESL and SESD in their content area or across the curriculum. Also, SESD/ESL specialists, if not all teachers, would benefit from exposure to topics including bilingual literacies, multilingual and intercultural approaches to ESL, and specialized SESD methods as part of their teacher education programs to prepare them better to assist students to sustain bilingualism. Also, sensitivity training might help teachers understand better the literacy, technological, and psychological-emotional challenges facing many refugee and immigrant students. Student support-staff in particular need specific preparation in cross-cultural counseling to address some of these challenges. These programs might embrace both preservice and inservice teacher professional development. Finally, and critically, the hiring of people of diverse and underrepresented groups as teachers, counselors, and administrators should complement these strategies. These professional development and hiring initiatives need to be extended to divisional officers, directors, consultants, and coordinators.

\section{TESL and Aboriginal Students}

Aboriginal students can face significant language challenges ranging from first-language loss to struggles with English as a second language (ESL) or standard English as a second dialect (SESD). To date, the TESL profession has remained largely aloof from Aboriginal second-language or dialect issues in Canada. Many justify this lack of attention by claiming that Aboriginal educators and their communities need more autonomy to address the protection of their first languages, cultures, and education. Meanwhile, Aboriginal educators remain highly suspicious of masked assimilation agendas of the state, and ESL can be perceived as an arm of that agenda. Yet at the same time, demographic trends indicate that Aboriginals are leaving northern rural communities and reserves to come to the city (Newhouse \& Peters, 2003; Norris, 2004), where increasing numbers of Aboriginal students are mainstreamed into English-dominated educational and community contexts outside direct First Nations' educational governance jurisdictions. Although their urban population can be clustered in communities, the Aboriginal people in these communities tend to be from varying linguistic and First Nation backgrounds.

To support Aboriginal communities and peoples in their aspirations for cultural survival and equitable academic, economic, and social opportunities, the TESL professional community has specific skills, methods, and knowledge in ESL, SESD, second-language acquisition, and bilingual educa- 
tion. At the same time, we need to become more informed about the feelings, aspirations, obstacles, and resistances of Aboriginal learners in English-language education programs. To this end, we need to promote greater dialogue and trusting relationships with Aboriginal learners and communities to make available this body of knowledge on ESL/SESD education while learning more about the specific learning needs of their members. In addition, we recognize the need to bring increasing numbers of Aboriginal teachers and professionals in as active members of the TESL professional community. Three areas TESL research and practice can develop to address these concerns are as follows.

Language development. Several Aboriginal language groups can be well served by TESL. One group are those in remote communities and reserves where their first, Indigenous language remains intact. These students may be unilingual Aboriginal speakers, Aboriginal English-dialect speakers, or bilingual students with limited English language skills. For these students, TESL can offer greater economic mobility and participation in the Canadian mainstream. Yet we understand the need to teach ESL/SESD in this context with bilingual, bicultural outcomes in mind. Another group are those students who come from families and communities with protracted exposure to English, but whose English remains a non-standard dialect. Specific approaches and programs need to be developed to address their needs for standard English as a second dialect (SESD) education as a conduit to fuller participation in Canadian mainstream economic and social life. This group may benefit as well from second-language education in their original Aboriginal language (Norris, 2003). The TESL professional community needs to enter into partnership with Aboriginal educators to support the language development of Aboriginal students, teachers, and communities.

Aboriginal adults should have access to similar workplace-targeted language supports currently available to newcomers. Many Aboriginals face the same obstacles as second-language speakers as newcomers, yet instead they tend to be viewed as lacking cultural knowledge, skills, or appropriate motivation. The workplace English-language standards and assessment tools of the Centre for the Canadian Language Benchmarks, for example, could be adapted for Aboriginal learners (see www.language.ca).

TESL in bilingual Aboriginal programs. This points to the need for TESL professionals to work with Aboriginal educators to explore ways to foster sustainable bilingualism across these diverse Aboriginal student populations. More community language programs would offer support to Aboriginal adults to sustain the home use of the first language and/or dialect while helping them learn the appropriate English language uses for academic and workplace uses.

Implications for professional development. One area that needs to be further developed is TESL training for Aboriginal educators of diverse backgrounds. 
Serious consideration needs to be given to developing programs and hiring Aboriginal teacher educators at the university and postsecondary level capable of teaching these specialized courses. In addition, we would support the development of a cohort in teacher education pairing SESD/ESL and Aboriginal language (Cree or Ojibway) educators to support the development and implementation of sustainable bilingual programs for Aboriginal and northern communities. Elders and Aboriginal leaders with specialized linguistic or cultural knowledge need to be targeted for special TESL/TSESD support. Also, classroom aides are commonly hired from the Aboriginal community to broker the cultural and linguistic knowledge of mainstreamed Aboriginal students with that of the teacher and mainstream classroom and school. These paraprofessionals are an important resource and should be encouraged and supported to enter the teaching profession if they are interested.

\section{TESL and Deaf (ASL) Students in Bilingual-Bicultural Programs}

The term Deaf, for the purpose of this article, is used when referring to any person or group of people that use American Sign Language (ASL) as their first language. Increasingly, the Deaf community and Deaf educators are coming to view Deafness from a cultural and linguistic perspective. This is leading to a shift from a special-education to a bilingual-ASL/ESL model of Deaf education (Evans \& Seifert, 2000). In these bilingual-bicultural programs, content is taught using ASL and English simultaneously in order to develop competence in both languages. American Sign Language is used for communication, instruction, and thinking, whereas English is used for reading and writing and is learned as a second language. In this respect, increasing numbers of Deaf educators are turning to TESL theory and practice to improve their approaches to teaching English to this student population. Yet to be factored into TESL for Deaf students is the multicultural, multilingual nature of many of their home environments. In this respect, although the first language of this population of Deaf students may be ASL, their home language and culture may not be English and Canadian (e.g., it could be one of many heritage or Aboriginal languages and cultures). According to Anderson (1997), Deaf students are probably more multicultural and diverse than the general school-aged population. Multicultural Deaf people interact in multiple cultures: the Deaf community, the predominantly white hearing community, their hearing ethnic or racial group, and their Deaf ethnic or racial group. This can be lost in the focus on ASL/ESL bilingual-bicultural programming.

Language development. Specialized approaches to TESL need to be developed to serve the special needs of this student population. New approaches to bilingual literacy education that do not involve the traditional progression 
through oral, spoken, read, and written forms of communication are helpful in that Deaf students do not enter literacy in this hearing-centered manner.

TESL in bilingual-bicultural programs for the Deaf. Consistent with a multilingual, intercultural approach, English as a second language instruction needs to complement, not replace, the central place of ASL in the instruction of Deaf students. Their first language for interpersonal interactions is ASL, and their second language (e.g., ESL) is for literacy. So Deaf students need much ASL support in the process of learning second language literacy in ESL (Evans \& Seifert, 2000) and should be encouraged to use a great deal of translation. Also, because Deaf students are moving across cultures (Deaf and hearing cultures), they need to learn cultural differences explicitly in the context of their language and literacy instruction.

Implications for TESL teacher preparation. We need greater collaboration between Deaf and ESL educators and researchers in teacher education programs, schools, and individual courses. Evans and Seifert (2000) emphasize the need for more Deaf teachers to serve as role models for their unique language and literacy practices. This requires the active recruitment of Deaf students to enter the teaching profession, not unlike that encouraged for Aboriginal and minority communities.

\section{TESL and International Students}

Recognizing the increasing numbers of courses and programs serving international students in Manitoba, the TESL community supports appropriate provisions and services for these students. As human resources for enhancing global awareness in Canadian students, international students require suitable opportunities for sharing their cultures and experiences with Canadian students, schools, and communities. At the same time, given the challenges these students experience coming here, we recommend that programs serving international students conduct a needs assessment and receive extensive support to accommodate the special needs and issues facing these students.

From a more critical perspective, we need more information about where the government stands with respect to the recruitment of international students. If it is all about "selling a service" to rich members of an international corporate elite, then this has little to do with enhancing equity and diversity and respecting Canadian multiculturalism. This does appear to be behind the rhetoric of the federal government (Trade and Industry and Foreign Affairs), and there is little to suggest that it is not also the major orientation of the Manitoba government and other provincial, municipal, and school division (district) policies. It is our responsibility as TESL professionals to challenge the commodification and exploitation of ESL students, teachers, and public programs by governments in the service of profits and commercial interests. 
Language development. Many international students are here for a crosscultural, immersion experience; they are not here to learn English to nativespeaking competence, nor to assimilate into the Canadian culture. They are not merely learning language; optimally, they are learning intercultural sensitivity and intercultural identities.

TESL and global citizenship education. Like Canadian citizenship, global citizenship increasingly calls for multilingual, multicultural abilities and unique educational programs to cultivate them.

Implications for professional development. Teachers need to be sensitive to these students' cultural differences and their need to sustain these cultural differences while gaining appreciation and understanding of the broader Canadian context.

\section{Specific Recommendations}

Given the decisive place of TESL in serving or undermining multiculturalism, and given the diverse students we serve and the varied responsibilities owed to them, some practical steps can be taken to make ESL work in the public education system more consistent with the principles and spirit of Canadian multiculturalism. In the following section, we elaborate on a number of proposals from our organizations' (TEAM and TESL Manitoba) joint response to Manitoba Education, Citizenship and Youth's draft Action Plan for Ethnocultural Equity.

\section{Aboriginal Education}

Overall, this initiative to renew and reaffirm Manitoba Education's policies on diversity and equity in education is laudable. We believe ESL must be situated in the broader context of second-language education in a multilingual, multicultural world (Canadian and global). In particular, SESD/ESL teachers working with Aboriginal students need to coordinate their activities with teachers of the Aboriginal language. To support the maintenance of Aboriginal languages and cultures, it is important to develop bilingual SESD/ESL and Aboriginal language programs for Aboriginal students. At the same time, we need to go beyond understanding multiculturalism merely as cultural retention, with a focus on issues of culturally appropriate contents and ways to teach Aboriginal students. A limited cultural retention perspective neglects the equity dimension of multiculturalism, which can be considerably furthered by offering Aboriginal students English language support. At present, this tends to be provided by resource centers that can treat the language problem as a disability rather than as a second-language issue. 


\section{Parental and Community Education}

The Ministry of Education proposed a promotional campaign to encourage second-language learning targeted to parents and students. We believe there is a larger need here. Parents of ESL students tend to remain in the periphery of their children's education. It is important that any promotional campaign include systematic outreach to these parents. They need to be invited, encouraged, and mentored to participate in all decision-making, but especially decision-making about multicultural, ESL, Aboriginal, and /or heritage language maintenance programs in schools. We need to hear from parents and to include their perspectives and concerns in the curriculum and community of the school. This could involve cross-cultural teacher preparation and training for welcoming and interacting with these parents. Diverse and representative parent associations can be important resources for developing community and adult education programs and services as well. For example, Victor Mager School in Winnipeg is a model for the integration of diverse parents into the life of the school at all levels, with services including an early childhood center and adult education programs for literacy and adult ESL.

Furthermore, these diverse perspectives need to be voiced by appropriate representatives of the communities who are well informed about their communities. They can be complemented with individuals who are informed about research in the relevant curricular and program areas (e.g., anti-racist education). To identify such representatives, we need to move beyond a narrow definition of school stakeholders to include the voices of community leaders and learners. If they lack sufficient background to participate meaningfully in such curricular and school development teams, then participatory action research projects and other forms of support should be offered to assist them to gain such expertise. In turn, schools will gain valuable insights and offer more than lip service to the concept of parental and community involvement.

\section{Government Responsibilities}

The Department (MECY) recognized the need to increase diversity and equity contents on its Web site. We believe that, beyond content, the Web site should include languages other than only English to model the type of diversity and multilingualism that it officially proposes. Although the Department proposes building a more diverse staff, it is important to ensure cross-representation in the target groups. For example, it is important to have gender and ability representation from underrepresented groups. In addition, plans for inservice teacher professional development in Aboriginal and diversity education should include community representatives (parents, learners, community leaders), who offer different perspectives from experts on TESL, multilingualism, multiculturalism, anti-racist education, human rights education, and other related areas. 
Many provincial education systems, including MECY, are developing various sets of indicators to monitor the system. We would like to see a longitudinal tracking study of ESL learners in the province to find out how well our programs are serving them. Such studies need to be developed in consultation with various stakeholders, including representatives from K-12 (K-S4) and adult ESL teachers and teachers' associations, ministries of education, postsecondary institutions, and TESL education programs.

In December 2003, the Department released the results and recommendations of its Kindergarten to S4 ESL Program Review (www.edu.gov.mb.ca/ $\mathrm{ks} 4 / \mathrm{cur} /$ diversity/esl/program_review.pdf). As TESL professionals, we applaud this ESL program review, but we advocate rapid implementation of its recommendations. We need to educate the public, including teachers and school administrators, on the vital importance of ESL and SESD education to the provision of equity in Canada. Not only is such equity implicit in Canada's multicultural policies outlined in the Canadian Charter and the Multicultural Act of 1988, but it is central to our responsibility as public educators to serve this generation of newcomers and Aboriginal learners, who constitute a significant portion of the Canadian population. In addition, we encourage future initiatives based on continual tracking, review, and renewal, and we support a sustained sharing and comparison with other provinces and states.

\section{Curricula and Materials}

Among the resources that the province develops for teachers to assist with bringing a focus on diversity into the curricula, there is a need for explicit materials dealing with discrimination based on language ability. These curricula and supplements need to be designed for all students, not just those students of marginalized groups. We need to embrace cultural diversity at a profound level in our curricula to embody intercivilization awareness, dialogue, and active respect for the sophistication and diversity of human perspectives across cultures. This needs to go beyond social studies to include all subject areas, including discussions of human values, science, history, and so forth. We must not let the secular-religious divide exclude important conversations in our education.

In addition, we need to integrate the history of subject areas explicitly in the curriculum. We need to move beyond the limited Western view of such subjects to understand their iteration historically and at present across cultures. This can include discussion of individuals of diverse backgrounds who have contributed to our understanding of the subject matter. This would include science and math, not just the traditional "cultural" subjects of social studies and language arts. This is a way to enrich the curriculum, not burden it with more tasks. Furthermore, it is a way to invite underrepresented people into the teaching of those subject areas. 
There need to be more financial and networking supports for stakeholders to contribute to the development of curriculum and curricular materials. At present, generous funds are available for academic research on multicultural and multilingual education, as well as for community networking and consultations, including in the development of performancebased competence standards and assessment by and for government agencies; however, few resources are available for these same stakeholders and stakeholder organizations to collaborate to disseminate their collective wisdom through the development of curricular resources for teachers and learners. At present, this is left largely to the private sector. Although many community organizations have attempted to develop classroom resources that might promote greater intercultural awareness, they tend to gather dust if inadequately linked to the mandated curriculum and so remain excluded from official lists of recognized materials. The Department should work more actively with these organizations to support their materials initiatives.

\section{ESL, SESD, and Content-Area Instruction}

As the Department develops professional learning opportunities for educators to do with inclusive schools, we specifically recommend that contentarea teachers across the curriculum need to be explicitly educated through professional development and curricular documents in academic language issues pertinent to their subject area. Such "ESL infusion" is important for inclusive education for ESL and Aboriginal students to assist them to master academic language skills beyond conversational English.

\section{Program and School Administration}

We also stress the need for the inclusion of administrators in such professional development. Administrators have both facilitative and instructional leadership roles, but they usually have little or no education in the issues about multilingualism and multiculturalism. We believe that inclusive education is part of a broader multicultural educational agenda.

\section{Safe Schools Agenda}

As schools and divisions work to build safe schools, a necessary step in the inclusion of diverse students is achieving a healthy school climate. ESL students are often the victims of school violence, and anti-bullying is too limited an agenda to ensure these students are offered a psychologically, not just physically, safe environment for learning. Accordingly, we call for the cultivation of empathy and compassion in students as part of the safe-school initiatives, not just the avoidance of bullying behaviors. This may justify the inclusion of diverse approaches to values from both religious and secular sources. One way to accomplish this is to introduce conversations about human rights, moral education, and character education from a broader, cross-cultural perspective. At present, there appears to be stigmatization and 
avoidance of conversations about compassion, empathy, and moral development in schools; however, these conversations need to be conducted such that no one is offended or excluded.

Accordingly, we believe that the integration of an antiracist-antibias agenda for safe schools calls for explicit education in critical reasoning and emotional sensitivity and awareness. Such programs would include sustained cultural and historical critiques, but also explicit support in the cultivation of empathy and compassion in relations between students. The intention of such dual focus programs should be to encourage the appreciation of diversity and equity, but also a sense of solidarity and shared participation among students. Ellsworth (1989), for example, conducted a classic action research study of the negative and conflict-ridden outcomes of an exclusively critical approach to anti-racist education, entitled "Why Doesn't This Feel Empowering?"

\section{Diverse Teaching Force}

In order to build a teaching force that reflects our diverse population, we must increase the number of Aboriginal and culturally diverse students in faculties of education. As provincial governments and universities work to this end, they should establish policies in teacher education admission procedures on how to use and assess language abilities and how to discriminate between accents and actual communication problems in prospective teachers. Attention needs to be paid to the interview admission criteria, process, and how it is weighted. Special consideration could be given to Aboriginal and ESL applicants; for example, more weight could be placed on the oral interview, with TESL and Aboriginal education specialists conducting the interviews to identify potential language supports they may require. Also, ESL and Aboriginal students interested in pursuing teaching careers need more oral and written language support in their baccalaureate programs to help augment their academic standing.

We advocate the development of workplace English language benchmarks for the teaching profession to support the inclusion of underrepresented groups in the teaching profession, either as internationally trained professionals (ITPs) or as prospective teacher education students. These benchmarks should not be applied as gatekeepers (i.e., as high-stakes testing), but as assessment frameworks to guide the development of programs and outcomes in English language and cultural skills targeted to the teaching profession. Such programs should include extensive practica with support in the local schools as well. This should not be limited to subject areas where there is a shortage of Canadian certified teachers (e.g., physics, math).

Students of underrepresented groups with challenges in English language and Canadian cultural competence could be referred to these 
benchmarked ESL access programs as part of a broader, proactive recruitment policy. Alternatively, adjunct programs could be developed alongside preservice programs to accommodate these students as they complete their credentials. The development of such benchmarks could be modeled on those developed by the Centre for the Canadian Language Benchmarks for internationally trained nurses (Canadian English Language Benchmark Assessment for Nursing, CELBAN). Also, to further the development of a more representative teaching force, the issue of credential recognition for newcomers needs to be extended to the teaching profession. We need a competence-based approach to credential recognition to move beyond exclusive attention on credit hours to consider more holistic, broader-based criteria, and perhaps prior learning assessments.

The Manitoba Action Plan (www.edu.gov.mb.ca/ks4/docs/discuss/ diversity/) acknowledges the need to promote education as a career for Aboriginal and culturally diverse youth. To this end, we recommend conducting participatory action research in targeted communities to understand the obstacles and resistances to members entering the teaching profession. Also, it is important to give high visibility to existing teachers from these communities for them to serve as models and mentors for prospective and interning students. If family and community involvement is encouraged and visible, then it can encourage families to see education as a positive career choice. There needs to be active public education on the prospects in, and benefits of, the teaching profession. Furthermore, it seems that many of these underrepresented groups tend to enter the system as paraprofessionals. One strategy might be to offer additional financial support for these people to upgrade their credentials to enter the teaching profession.

\section{Conclusion}

The professional responsibilities of ESL/SESD educators have shifted significantly in the last decades from serving as agents of assimilation and integration to promoting equity, diversity, and Canadian multiculturalism. This has extended ESL teachers' professional responsibilities from the restricted domain of English-language studies to broader concerns with multilingualism, multiculturalism, first-language and cultural maintenance, and the promotion of equity, diversity, and anti-racism through education. Professional organizations such as TESL Manitoba and TEAM play a key role in describing and realizing the possibilities outlined in this vision. The positions reflected in this article were arrived at through extensive conversations at meetings, conferences, and informal gatherings; these need to continue. In learning to communicate across our increasingly diverse and varied membership, which includes K-12 (K-S4) and adult instructors, program administrators, ESL instructors, TESL professors, ESL/SESD TAs, volunteers, and learners, we hope to learn to respond more fully to the needs of our diverse 
constituents and communities. As we see it, it is not so much about expanding our profession as about expanding our ethical and professional responsibilities.

\section{Notes}

${ }^{1} \mathrm{~T} / \mathrm{ESL}, \mathrm{T} / \mathrm{ESOL}, \mathrm{T} / \mathrm{EIL}, \mathrm{T} / \mathrm{EFL}, \mathrm{T} / \mathrm{EAL}, \mathrm{T} / \mathrm{EML}, \mathrm{SESD}$ : these acronyms stand for the following, the $\mathrm{T} /$ referring to Teaching:

ESL: English as a Second Language (commonly used in Canada);

ESOL: English to Speakers of Other Languages (commonly used in the USA);

EIL: English as an International Language;

EFL: English as a Foreign Language;

EAL: English as an Additional Language;

EML: English as a Missionary Language;

SESD: Standard English as a Second Dialect (commonly used for teaching standard English to speakers of nonstandard dialects, including Indigenous North Americans and African-Americans).

${ }^{2}$ See Kymlicka (1995) for a good discussion of the tensions between identity (shared history, traditions, religions) and values approaches to building unity in a multicultural state. In particular, there is a footnote on the implications for citizenship education (p. 238, note 14).

${ }^{3}$ See Orend (2002) for an excellent introductory framework for an advanced human rights curriculum.

\section{The Authors}

Seonaigh MacPherson is an assistant professor in TESL and second-language education in the Department of Curriculum, Teaching and Learning at the University of Manitoba. She is on the Executive of TEAM, TESL Manitoba, and the Centre for the Canadian Language Benchmarks.

Diana Turner is President of TESL Manitoba and an English-language arts and ESL teacher in a Pembina Trails high school in Winnipeg.

Ranya Khan is on the Executive of TESL Manitoba and is a coordinator of the CTESL program at the University of Manitoba.

Warren Hingley is Past-President of TESL Manitoba, a former ESL/SESD teacher, and current Principal in a Louis Riel School Division elementary school in Winnipeg.

Ann Tigchelaar is President of TEAM and an adult and settlement ESL teacher at Victor Majer, part of Louis Riel School Division.

Lori Dustan Lafond is a teacher of the Deaf in a bilingual-bicultural school for the Deaf in Winnipeg where English is a second language. She is a member of TESL Manitoba.

\section{References}

Anderson, G. (1997). In their own words: Researching stories about the lives of multicultural Deaf people. Deaf Studies, V, Toward 2000, 1-15.

Bennett, M. (1986). A developmental approach to training for intercultural sensitivity. International Journal of Intercultural Relations, 10, 179-196.

Burnaby, B. (2002). Reflections on language policies in Canada: Three examples. In J.W. Tollefson (Ed.), Language policies in education: Critical issues (pp. 65-89). Mahwah, NJ; London: Erlbaum.

Citizen's Forum on Canada's Future. (1991). Report to the people and government of Canada. Ottawa, ON: Supply and Services.

Clarke, P.B. (1996). Deep citizenship. London; Chicago, IL: Pluto Press. 
Coelho, E. (2003). Adding English: A guide to teaching in multilingual classrooms. New York: Pippin Press.

Crystal, D. (2000). Language death. Cambridge, UK: Cambridge University Press.

Ellsworth, E. (1989). Why doesn't this feel empowering? Working through the repressive myths of critical pedagogy. Harvard Educational Review, 59, 297-324.

Evans, C.J., \& Seifert, K.L. (2000). Fostering the development of ESL/ASL bilinguals. TESL Canada Journal, 18(1), 1-16.

Goldstein, T. (2003). Teaching and learning in a multilingual school: Choices, risks, and dilemmas. Mahwah, NJ; London: Erlbaum.

Kim, Y.Y. (2001). Becoming intercultural: An integrative theory of communication and cross-cultural adaptation. Thousand Oaks, CA; London: Sage.

Kouritzin, S. (1999). Face(t)s of first language loss. Mahwah, N]; London: Erlbaum Associates.

Kouritzin, S.G., \& Mathews, P.G. (2002). Policies affecting ESL instruction in Manitoba. Canadian Journal of Educational Administration and Policy, 22. Retrieved September 10, 2004, from:http//umanitoba.ca/publications/cjeap/articles/kouritzin.html

Kubota, R. (2004). Critical multiculturalism and second language education. In B. Norton \& K. Toohey (Eds.), Critical pedagogies and language learning (pp. 30-52). Cambridge, UK; New York: Cambridge University Press.

Kymlicka, W. (1995). Multicultural citizenship: A liberal theory of minority rights. Oxford, UK: Clarendon Press.

LoBianco, J., Liddicoat, A., \& Crozet, C. (1999). Striving for the third place: Intercultural competence through language education. Melbourne: National Languages and Literacy Institute of Australia.

MacPherson, S. (2003). TESOL for biolinguistic sustainability: The ecology of English as a lingua mundi. TESL Canada Journal, 20(2), 1-22.

MacPherson, S., \& Tigchelaar, M. (2004). New directions: Human rights education for families. Edmonton, AB: Indo-Canadian Women's Association.

Magsino, R. (1995). Multiculturalism in schools: Is multicultural education possible and justifiable? In L. Roberts \& R. Clifton (Eds.), Contemporary Canadian educational issues (pp. 253-270). Scarborough, ON: Nelson.

Martin-Jones, M., \& Saxena, M. (1995). Supporting or containing bilingualism? Policies, power asymmetries, and pedagogical practices in mainstream primary classrooms. In J.W. Tollefson (Ed.), Pouer and inequality in language education (pp. 73-90). Cambridge, UK; New York: Cambridge University Press.

Mato, F., \& Valentine, J. (1999). Selected ethnic profiles of Canada's young age cohorts. Ottawa, ON: Strategic research and analysis, Multiculturalism Program, Department of Canadian Heritage.

Newhouse, D., \& Peters, E. (Eds.). (2003). Not strangers in these parts: Urban Aboriginal peoples. Ottawa-Hull: Policy Research Initiative of the Government of Canada.

Norris, M.J. (2004). From generation to generation: Survival and maintenance of Canada's Aboriginal languages, within families, communities and cities. TESL Canada Journal, 22(1), $1-19$.

Orend, B. (2002). Human rights: Concept and context. Peterborough, ON: Broadview Press.

Tollefson, J., \& Tsui, A. (Eds.). (2004). Medium of instruction policies: Which agenda? Whose agenda? Mahwah, NJ; London: Erlbaum.

Willinsky, J. (1998). Learning to divide the world: Education at empire's end. Minneapolis, MN: University of Minnesota Press. 